Corrosion Science, 2007, Volume 49, Issue 2, Pages 858-876.

ISSN: 0010-938X

DOI:10.1016/j.corsci.2006.04.015

(C) 2006 Elsevier Ltd. All rights reserved.

http://www.sciencedirect.com/science/article/B6TWS-4KCGJ21-4/2/afcbb41cad3d4ac27fe16543fc043741

http://www.elsevier.com/wps/find/journaldescription.cws_home/260/description\#description

\title{
Kinetics of sharp intergranular corrosion fissures in AA7178
}

\author{
Tsai-Shang Huang, G.S. Frankel \\ Fontana Corrosion Center, Department of Materials Science and Engineering, The Ohio State University.
}

\begin{abstract}
During service in structural aircraft applications, AA7178 has been found to develop sharp intergranular corrosion (IGC) fissures, a special form of attack. A new laboratory approach to quantify the kinetics of sharp IGC fissure growth was developed in this work. Sharp IGC fissures, similar to those formed in service, grew in samples that were given an electrochemical pre-treatment and then exposed in a humid environment. The time for the first sharp IGC fissure to penetrate the thin sample was determined by visual observation of the back side of the sample. The depth of the sharp IGC fissure was determined by serial sectioning. The kinetics measured by this approach did not represent the fastest rates, but rather the rates of long sharp IGC fissures. Relative humidity had no measurable effect on fissure kinetics, indicating that there was little connection of the local sharp IGC fissure region with the outside environment. AA7178 in the as-received and T7 conditions exhibited slower sharp IGC fissure rates than in the T6 condition. The sharp IGC fissures were found to be filled with corrosion products, which possibly exert a stress that could play an important role in driving fissure growth. It is suggested that the sharp IGC fissure could be a form of SCC.
\end{abstract}

\section{Introduction}

AA7xxx alloys have been widely used in aircraft applications such as wing structures because of their high strength and low weight. However, they are very susceptible to localized corrosion. Corrosion is one of the main issues for aging aircraft. Different forms of localized corrosion, such as crevice corrosion, intergranular corrosion (IGC), pitting corrosion and exfoliation corrosion, were found in different locations of wing structures made of AA7xxx [1]. These localized corrosion sites are usually hidden and could result in structural failure if allowed to grow to critical dimensions.

AA7178-T6 plates develop a special form of attack, sharp IGC fissures, upon static unstressed exposure to aggressive atmospheric conditions [1]. These fissures seem to grow along grain boundaries, but their appearance is quite different than IGC that forms in AA7xxx during immersion in $\mathrm{NaCl}$ solutions [2-4]. They look similar to the sharp cracks caused by stress corrosion cracking in AA7xxx. In particular, they have been found to initiate in plate throughholes and propagate long distances [1]. Because the microstructure of such structural components is typically elongated in the direction of the applied stress, such sharp intergranular fissures often propagate parallel to the applied stress, which does not necessarily lead to a loss of strength. However, linking of different IGC sites can result in multi-site damage (MSD), which can lead to catastrophic failure. It is also possible that fatigue cracks can initiate at bends in IGC cracks, where the cracks can be perpendicular to the applied stress fluctuations.

The typical approach to aircraft maintenance requires replacement of any component that is found to contain corrosion. Maintenance costs could be reduced by allowing corrosion to exist as long as it did not critically degrade structural integrity. However, this requires an accurate 
prediction of corrosion kinetics. Therefore, measuring the kinetics of IGC is not only a way to evaluate corrosion susceptibility, but also very useful for a predictive model for corrosion.

The foil penetration technique is a simple and direct non-electrochemical method that has been used to measure localized corrosion growth kinetics [5,6]. It overcomes many of the limitations of electrochemical methods as there is no need to make assumptions regarding shape of the attack or hydrogen evolution current. By varying the sample thickness, sample orientation, solution environment and applied potential, the corrosion growth kinetics of the fastest-growing localized corrosion can be determined regardless of the corrosion growth path. Sehgal et al. studied the pit growth in AA1100-O and AA2024-T3 in different solutions by the foil penetration technique [6]. Zhang et al. also used this technique to measure the localized corrosion kinetics in AA2024 in $\mathrm{NaCl}$ solutions under a range of applied anodic potentials [7-9]. A limitation of this technique is that samples need to be tested during immersion in an aqueous environment. The corrosion morphology that develops in an aqueous environment is different than the sharp IGC fissures found during environmental exposure. Moreover, the corrosion environment for aircraft components is typically not immersion in an aqueous solution. Therefore, an approach that duplicates the sharp IGC fissures and provides the kinetics of their growth is needed.

This paper describes a new approach to quantify the growth kinetics of the sharp IGC fissures. It involves electrochemical pre-treatment of the sample followed by exposure in a humid environment. The pre-treatment creates localized corrosion sites on the sample surface that contain corrosion products and aggressive environments that stimulate subsequent attack in humidity. Such initiating environments can be found in crevices and through-holes in aircraft. Sharp intergranular fissures were found to grow from these sites and the growth kinetics were determined from the penetration time and the depth of corrosion. The effects of humidity and temper were studied and different analytical methods were used to analyze the sharp IGC fissures. The mechanism of the sharp IGC fissures is discussed.

\section{Experimental}

An $8.5 \mathrm{~mm}$ thick AA7178 plate cut from a retired KC-135 wing structure was provided by $\mathrm{S} \& \mathrm{~K}$ Technologies, Dayton, $\mathrm{OH}$. The composition determined by Inductively Coupled Plasma - Optical Emission Spectrocopy (ICP-OES) analysis is shown in Table 1. The nomenclature used for the plate orientations relative to the rolling direction is indicated in Fig. 1 [10] along with metallographic sections of the as-received AA7178 wingskin plate.

Samples were tested in the as-received condition, which is expected to be in the T6 temper. However, natural aging during an unknown service time might have occurred so samples were also tested following heat treatment to the T6 and T7 conditions. The heat treatment included solutionizing and artificial aging. The solution heat treatment was conducted in an air furnace at $465{ }^{\circ} \mathrm{C}$ for $1 \mathrm{~h}$, followed by water quenching [10]. The T6 temper was then produced by artificial aging at $120{ }^{\circ} \mathrm{C}$ in an air furnace for $24 \mathrm{~h}$ [10]. The $\mathrm{T} 7$ temper was produced by artificial aging at $120{ }^{\circ} \mathrm{C}$ for $4 \mathrm{~h}$ and then at $163{ }^{\circ} \mathrm{C}$ for $16 \mathrm{~h}$ in an air furnace after solution heat treatment [10].

Foil samples were sliced from this plate by a diamond saw. Samples were prepared in L and $\mathrm{T}$ directions relative to the rolling direction, Fig. 1. The side of each foil sample to be pretreated was first ground to 800 grit and the back side was polished to $1 \mu \mathrm{m}$. Alcohol was used during polishing to minimize corrosion before testing. The thickness of the samples was in the 
range of $0.45-0.60 \mathrm{~mm}$.

Table 1

Composition in wt\% of AA7178 wingskin plate determined by ICP-OES

\begin{tabular}{llllllllll}
\hline Alloys & $\mathrm{Si}$ & $\mathrm{Fe}$ & $\mathrm{Cu}$ & $\mathrm{Mn}$ & $\mathrm{Mg}$ & $\mathrm{Cr}$ & $\mathrm{Zn}$ & $\mathrm{Ti}$ & $\mathrm{Al}$ \\
\hline AA7178 & 0.04 & 0.28 & 1.95 & 0.056 & 2.76 & 0.19 & 6.91 & 0.053 & Bal. \\
\hline
\end{tabular}

Electrochemical pretreatment was performed on an area of about $41 \mathrm{~mm}^{2}$ on the ground side of the foil sample. The potential was controlled at $-725 \mathrm{mV} \mathrm{SCE}$ in $1 \mathrm{M} \mathrm{NaCl}$ solution. Most samples were pretreated for two hours, but a few samples were pretreated for one hour for comparison. Prior work indicated that these times are insufficient for localized corrosion to penetrate samples of the thickness used in this work [4]. After pretreatment, the corroded side was rinsed with water and wiped with dry cotton balls. The samples were then immediately placed in a humidity chamber with the polished side facing the transparent chamber wall to allow for observation. Care was taken through the entire process to keep the polished side dry and clean.

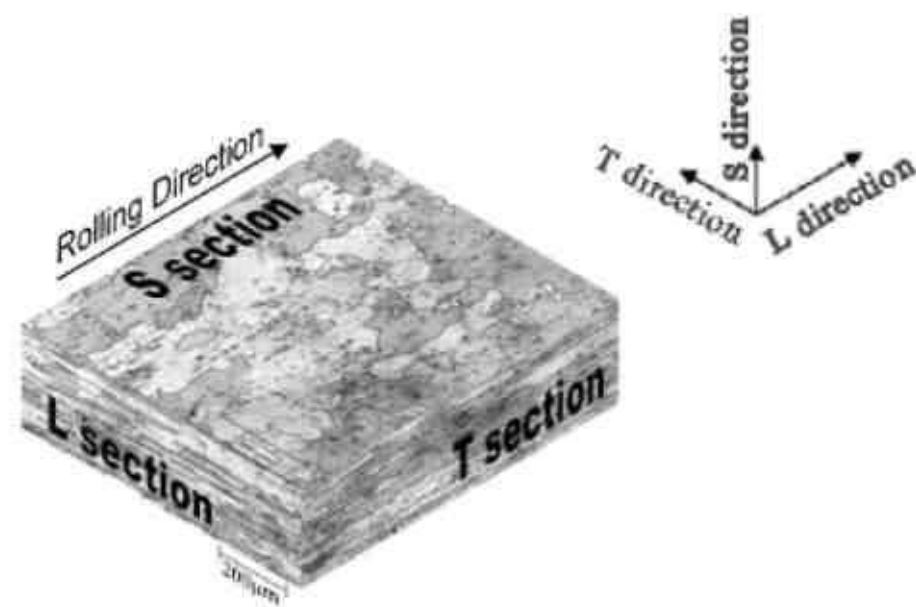

(a)

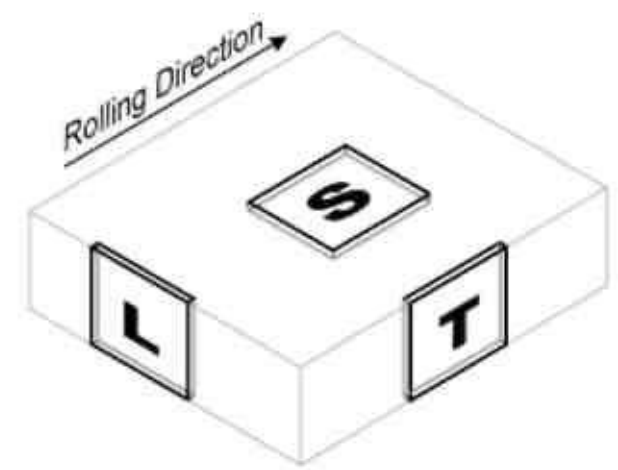

(b)

Fig. 1. (a) Metallographic sections of as-received AA7178 wingskin plate and the terminology used for the three orientations: L (longitudinal), T (long transverse) and S (short transverse). (b) Schematic diagram of foil sample orientation.

Table 2

The RH expected by equilibrium with the saturated solution of different salts at a given temperature [11] and measured $\mathrm{RH}$ at room temperature 


\begin{tabular}{lll}
\hline Salt & $\begin{array}{l}\text { Expected } \mathrm{RH}(\%) \text { at } \\
\text { given temperature [1] }\end{array}$ & Measured RH (\%) \\
\hline $\mathrm{Na}_{2} \mathrm{SO}_{4} \cdot 10 \mathrm{H}_{2} \mathrm{O}$ & $93\left(20^{\circ} \mathrm{C}\right)$ & 96 \\
$\mathrm{NH}_{4} \mathrm{Cl}$ & $79.5\left(20^{\circ} \mathrm{C}\right)$ & 83 \\
$\mathrm{NaBr} \cdot 2 \mathrm{H}_{2} \mathrm{O}$ & $58\left(20^{\circ} \mathrm{C}\right)$ & 64 \\
$\mathrm{Mg}\left(\mathrm{NO}_{3}\right)_{2} \cdot 6 \mathrm{H}_{2} \mathrm{O}$ & $52\left(24.5^{\circ} \mathrm{C}\right)$ & 58 \\
\hline
\end{tabular}

The relative humidity $(\mathrm{RH})$ in the chambers was controlled by equilibration with a saturated solution of a chosen salt. The expected [11] and measured $\mathrm{RH}$ values for four different salts are shown in Table 2 . The humidity chambers were $250-\mathrm{ml}$ glass beakers containing about $100 \mathrm{ml}$ of saturated solution and were sealed with polymeric film. The humidity in a chamber was found to reach a stable value within $36 \mathrm{~h}$. The measured $\mathrm{RH}$ values are higher than the expected values by a small amount.

The foil penetration in humidity test started when the pre-treated samples were placed in the humidity chambers. The condition of the polished back side of each sample was recorded daily using digital photography through the glass beaker. The appearance of corrosion on the polished side indicated that sample had been penetrated, and the test was stopped. The penetration time was recorded and the sample was removed to a freezer for storage until examination by serial sectioning. Details of the serial sectioning method are given below.

\section{Results and discussion}

\subsection{Selective grain attack and sharp IGC fissures}

Fig. 2(a) is a cross-sectional optical micrograph of the as-received AA7178 sample after an electrochemical treatment in $1 \mathrm{M} \mathrm{NaCl}$ at a potential of $-725 \mathrm{mV} \mathrm{SCE}$ for $15 \mathrm{~h}$. This potential is above the second breakdown potential in deaerated $1 \mathrm{M} \mathrm{NaCl}$ solution of around $-745 \mathrm{mV}$ SCE [4]. The top surface of this sample, an L surface, was exposed during the pretreatment, and the pit-like cavities that grew in the $\mathrm{L}$ direction represent a typical corrosion morphology generated by such an electrochemical treatment. Localized corrosion resulted in dissolution of selected grains, but then the attack stopped at the grain boundary. Similar attack was generated by a similar electrochemical treatment of AA7075-T6, Fig. 2(b). This type of corrosion has been termed selective grain attack [12]. 


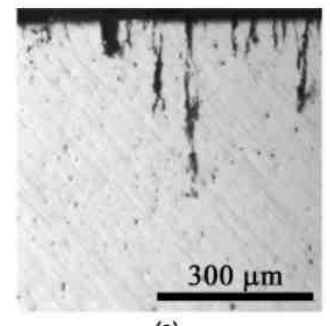

(a)

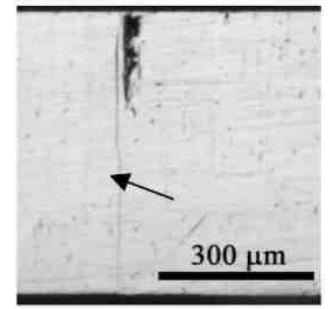

(c)

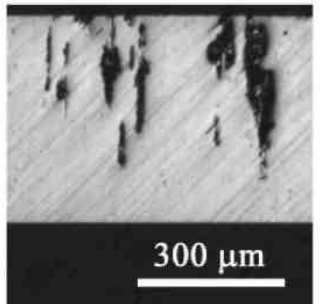

(b)

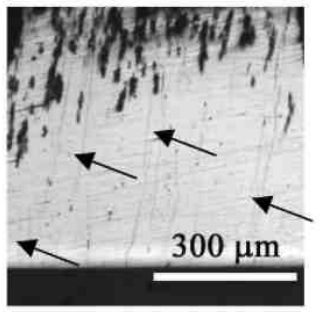

(d)

Fig. 2. Selective grain attacks and sharp IGC fissures. Sharp IGC fissures are pointed out by arrows. (a) AA7178T6: polarization in $1 \mathrm{M} \mathrm{NaCl}$ at a potential of $-725 \mathrm{mV} \mathrm{SCE}$. (b) AA7075-T6: polarization in $1 \mathrm{M} \mathrm{NaCl}$ at a potential of $-725 \mathrm{mV}$ SCE. (c) AA7178-T6: polarization in $1 \mathrm{M} \mathrm{NaCl}$ at a potential of $-725 \mathrm{mV}$ SCE followed by high humidity exposure. (d) AA7075-T6: polarization in $1 \mathrm{M} \mathrm{NaCl}$ at a potential of $-580 \mathrm{mV}$ SCE followed by high humidity exposure.

Fig. 2(c) is a cross section of an as-received AA7178 sample following electrochemical pre-treatment and subsequent high humidity exposure. In addition to the selective grain attack formed during the pretreatment, a sharp IGC fissure pointed out by an arrow is also evident, and it looks very much like the attack formed during natural exposure of aircraft wingskins. Fig. 2(d) shows an AA7075-T6 sample after pretreatment at a higher potential of -580 mV SCE, which generated more selective grain attack, and then exposure at high humidity. Sharp IGC fissures also formed in this alloy. Note that these images were not etched and special care was taken during polishing to prevent vertical scratches that could interfere with the identification of the vertical fissures. These results indicate that the sharp IGC fissures grew in high humidity environment from the selective grain attack sites. In fact, the sharp IGC fissure in Fig. 2(c) is seen to be connected to the selective grain attack near it.

The growth rates of the sharp IGC fissure were obtained in a fashion similar to the approach used by the foil penetration technique [5,6], which measures the penetration time for samples with different thickness and then inverts the relation to get the corrosion depth as a function of time. Therefore, two important parameters need to be determined: penetration time and length of the sharp IGC fissure. The sensing mechanism used in the standard foil penetration setup, a drop in resistance between the sample and a $\mathrm{Cu}$ backing foil separated by a thin paper sheet, was attempted as a means of determining penetration time for the sharp IGC fissures growing during high humidity exposure. However, the corrosive solution present in the fissure was insufficient to wet even very thin paper to the extent required to result in a measurable decrease in resistance, so an alternative approach was required.

\subsection{Determination of penetration time}




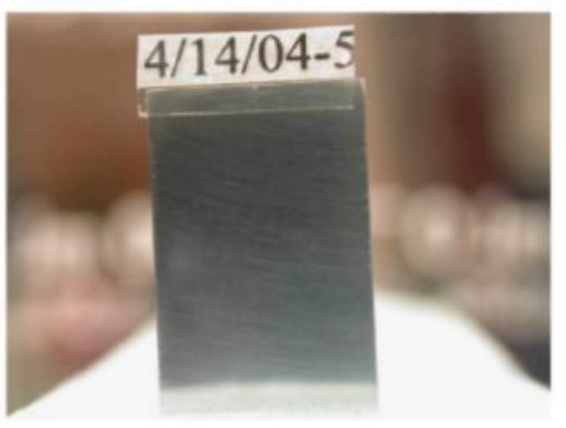

(a)

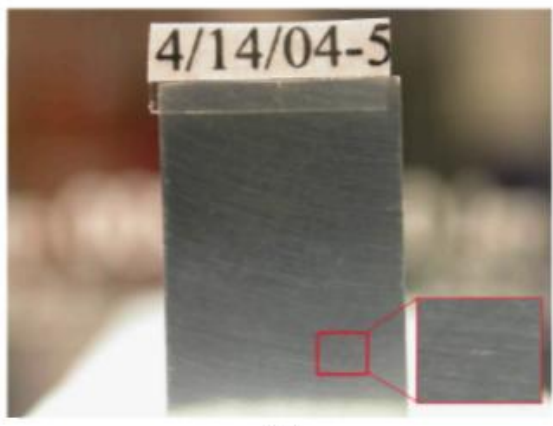

(c)

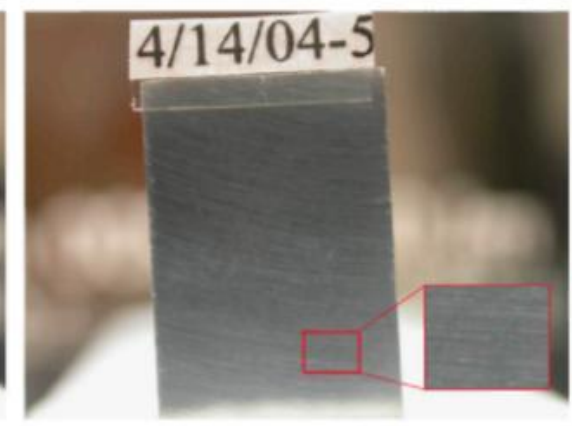

(b)

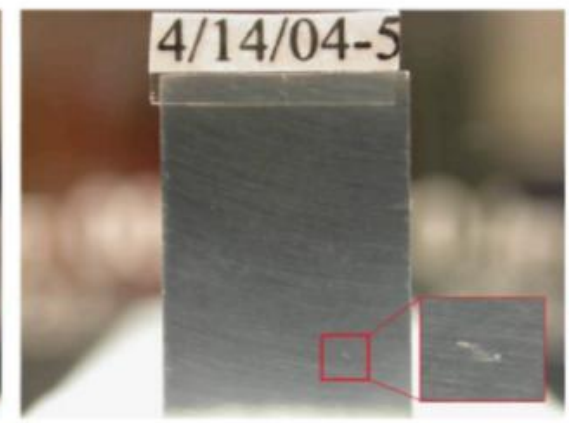

(d)

Fig. 3. Determination of the sharp IGC penetration time. (a) 1 day; (b) 15 days: no pit shown; (c) 16 days: first sign of penetration; (d) 17 days: corrosion products oozed out.

The penetration time was determined by monitoring the backside of each sample using high resolution digital photographs. Such images were recorded daily without removing the sample from the chamber so that the humidity exposure was uninterrupted. It is very difficult to notice a sharp IGC fissure when it first emerges on the backside because it is so small. However, after a few days, the penetrated site is easily observed because it grows as corrosion product exudes out of the site. Fig. 3(a)-(d) are backside images of an as-received AA7178 sample, taken right after pre-treatment, and after 15, 16 and 17 days respectively. A penetration site shown in Fig. 3(d) indicates that the sample was penetrated after 17 days. By examining prior photos carefully at the location of the penetration, it was possible to determine accurately the penetration time, within the resolution of the sampling period. Fig. 3(c) shows a smaller penetration site at the same location as in Fig. 3(d), but Fig. 3(b) shows none. Therefore, the penetration of the sharp IGC fissure occurred between the times that the images in Fig. 3(b) and (c) were taken. The midpoint of the sampling period was used as the penetration time. When penetration of a sample was positively identified, it was removed from the humidity chamber and stored in a freezer to reduce the extent of further corrosion.

This experiment was not performed in a clean room, so dust particles occasionally appeared on the samples or cell walls. Such dust can look like a penetration site in a photograph. However, a penetration site grew larger with time whereas dust remained the same size.

\subsection{Determination of sharp IGC length}

The electrochemical pretreatment created localized corrosion attack inside the samples in the form of selective grain attack. Although the pretreated surface was rinsed with water and wiped with dry cotton balls after pretreatment, a certain amount of corrosion products or 
concentrated solution was believed to be trapped in those sites and they were the initiation sites for sharp IGC fissures. Fig. 2(c) and (d) clearly show that the corrosion morphology included both selective grain attack and sharp IGC fissures. To determine the growth kinetics of the sharp IGC fissures, it was necessary to differentiate the sharp IGC fissure length from the depth of the pretreatment selective grain attack. Serial sectioning was used to accomplish this.

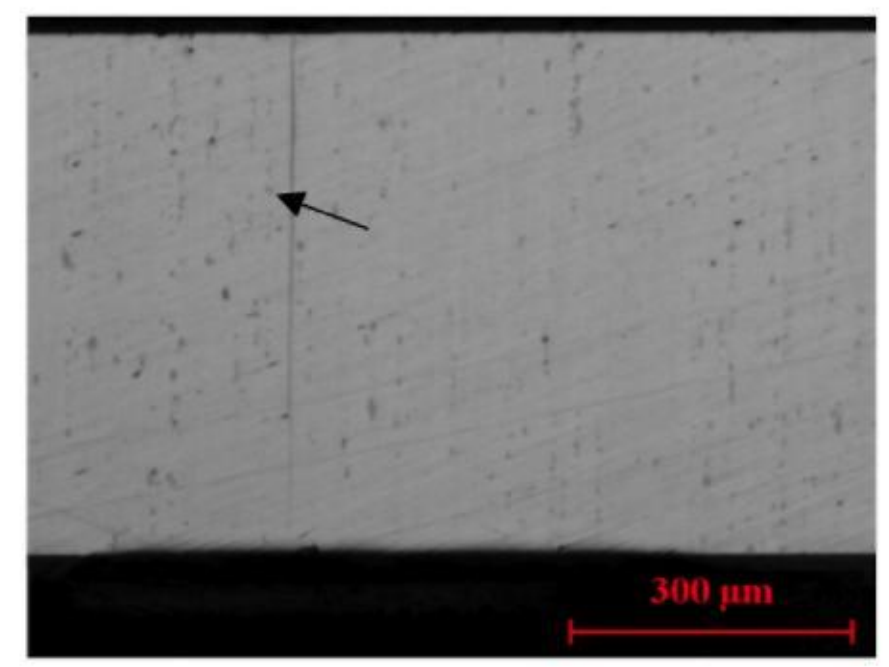

Fig. 4. Cross-section of a penetrated sample showing only a sharp IGC fissure (pointed out by arrow). A related selective grain attack is not seen on this section.

Fig. 4 is a section of an L sample exactly at the penetration site. It appears as if this fissure initiated at a site on the top pretreated surface and grew straight through the sample. However, the sharp IGC fissures were always associated with a selective grain attack site, and it is likely that selective grain attack initiating site for this fissure was somewhere else in the sample and not seen in this particular section. The sharp IGC fissures could grow in two or three dimensions, so one section is not enough to determine where the sharp IGC fissure began and how far it traveled. Therefore, careful serial sectioning is needed for the determination of the length of the sharp IGC fissures that grew during the humidity exposure period.

To facilitate tracking of the location of the sharp IGC fissures while polishing, small plastic balls were mounted as a reference along with the samples. Following penetration, every sample was mounted in epoxy and cross sectioned to a depth near to the penetration location. Optical microscopy was used to record the un-etched section. The sample was then repolished to view the sample at a deeper plane. The amount of material removed at each step was determined using a micrometer to measure the thickness of the sample after each step. Table 3 shows the average grain dimensions of the AA7178 wingskin plate in different orientations. Sectioning proceeded in the $\mathrm{T}$ direction when determining the depth of sharp IGC fissures in the L direction. Since the grain dimension in the $\mathrm{T}$ direction was $511 \mu \mathrm{m}$ on average, about $20-30 \mu \mathrm{m}$ was removed during each step so as not to miss important sections. The whole sharp fissure site was documented by sectioning, which required, on average about 20 sections per site.

The sharp IGC fissure length used for assessment of the growth kinetics was determined by careful examination of the serial sections. This determination was not straightforward because the sharp IGC fissures grew in 2 and sometimes 3 dimensions. Fig. 5 shows some important images from serial sections of a sample that penetrated after $706 \mathrm{~h}$. Fig. 5(c)-(f) show a sharp IGC fissure intersecting the backside at the bottom of the image. The sharp IGC fissure origin 
was taken as the point furthest away from the pretreated surface where it was connected to the pretreatment selective grain attack site. Fig. 5(c) shows the deepest intersection of the sharp IGC fissure and the selective grain attack. Therefore, the depth of the sharp IGC fissure was determined from this image, from this intersection point to the bottom of the sample.

Table 3

Grain dimension of AA7178-T6 wingskin plate

\begin{tabular}{lll}
\hline Orientation & Average $(\mu \mathrm{m}))$ & Standard deviation \\
\hline $\mathrm{L}$ & 1040 & 692 \\
$\mathrm{~T}$ & 511 & 261 \\
$\mathrm{~S}$ & 39 & 17 \\
\hline
\end{tabular}

Fig. 6 shows some important images from another sample that penetrated after $474 \mathrm{~h}$. The sharp IGC fissure that penetrated to the back side of the sample can be seen in Fig. 6(b)-(d). The deepest location of the selective grain attack associated with the sharp IGC fissure is marked P in Fig. 6(c). However, from these images, it is suggested that the origin of the sharp IGC fissure associated with the selective grain attack is at point $\mathrm{O}$, not point $\mathrm{P}$ in Fig. 6(c). The sharp IGC fissure began from the center, not the end, of the selective grain attack. Therefore, the depth of the sharp IGC fissure was measured from point $\mathrm{O}$ to the bottom of the sample in Fig. 6(c). 


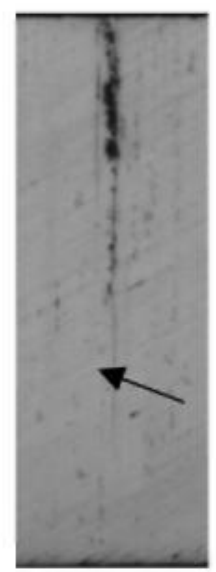

(a)

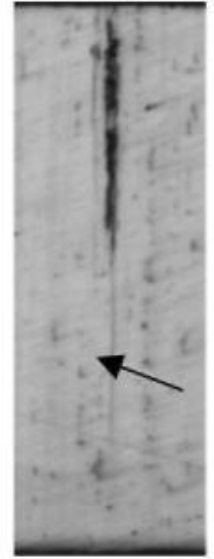

(b)

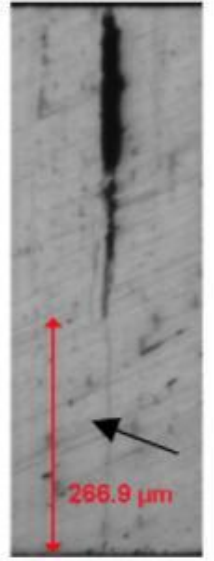

(c)

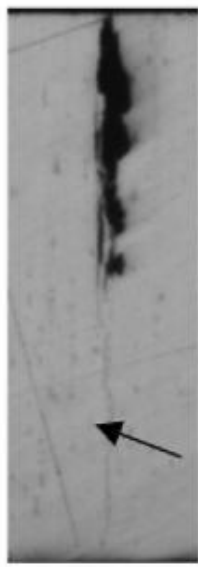

(d)

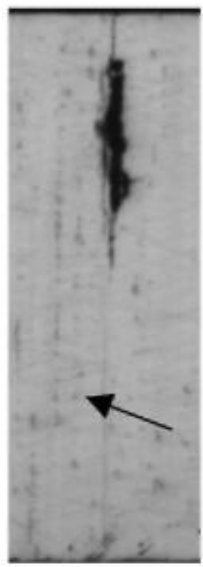

(e)

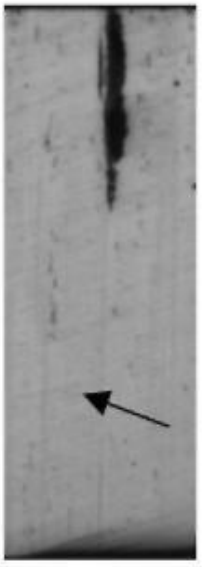

(f)

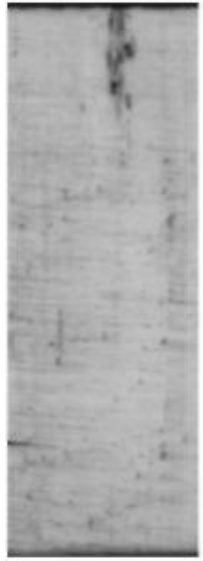

(g)

Fig. 5. Serial sections of a penetrated sample. A sharp IGC fissure (pointed out by arrow) grew from the end of a selective grain attack. $266.9 \mu \mathrm{m}$ was determined as the depth of this sharp IGC fissure.

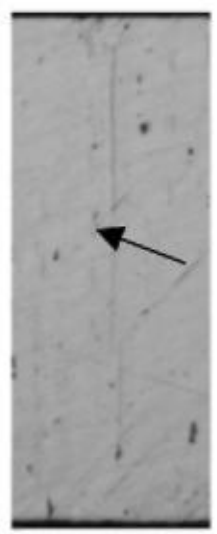

(a)

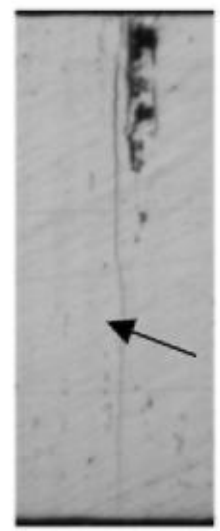

(b)

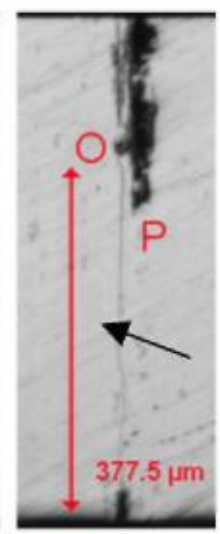

(c)

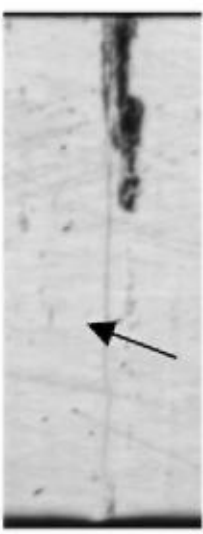

(d)

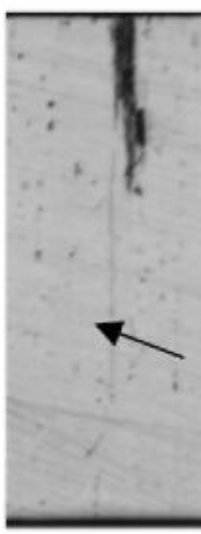

(e)

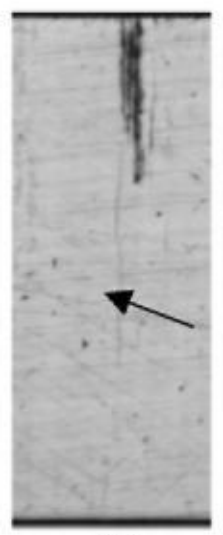

(f)

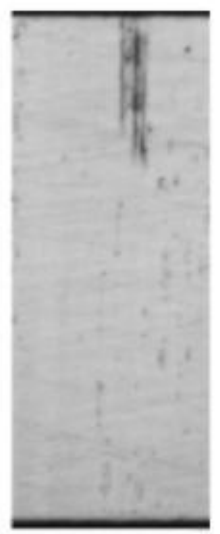

(g)

Fig. 6. Serial sections from a penetrated sample. The sharp IGC fissure (pointed out by arrow) did not begin from the end of the selective grain attack. $377.5 \mu \mathrm{m}$ was determined as the depth of this fissure.

\subsection{3-D image reconstruction}

To reveal the nature of sharp IGC fissure propagation inside the material, a 3-D image of a corrosion attack was reconstructed from the serial sections using the software package IMOD [13,14]. Fig. 7 shows a 3-D image of a sharp IGC fissure at different angles. This image was built from 29 serial sections of a sample. Each section was aligned vertically using the top surface and horizontally using the center of a plastic sphere that was mounted near the sharp IGC fissure site as a reference. The interval between each section ranged from 5 to $25 \mu \mathrm{m}$; however, they were evenly separated in the 3-D image with the total distance from the first section to the last equal to the sum of the intervals.

In Fig. 7(a), the 3-D image is oriented so as to view the corrosion attack in three dimensions. The selective grain attack was highlighted to be darker and is found in the upper right corner. The top edge was exposed during the pretreatment. In this orientation, the selective 
grain attack is viewed primarily from the $\mathrm{S}$ direction, so the dissolved grain appears large. The sharp IGC fissure propagated from the edge and bottom of the selective grain attack site in both the vertical (L) and horizontal (T) directions along grain boundaries. The sharp IGC fissure propagation traced out the grain boundary surface. The circled area in Fig. 7(a) shows where the L-T grain boundary surface that the sharp IGC fissure followed was offset by intersections with different grains in the S direction. Fig. 7(b) is the same 3-D image viewed from an orientation down the $\mathrm{T}$ direction. The sharp IGC fissure grew from only one side of selective grain attack. The grain offsets in the intergranular plane make the overlapped sections appear to have width in the $\mathrm{S}$ direction.
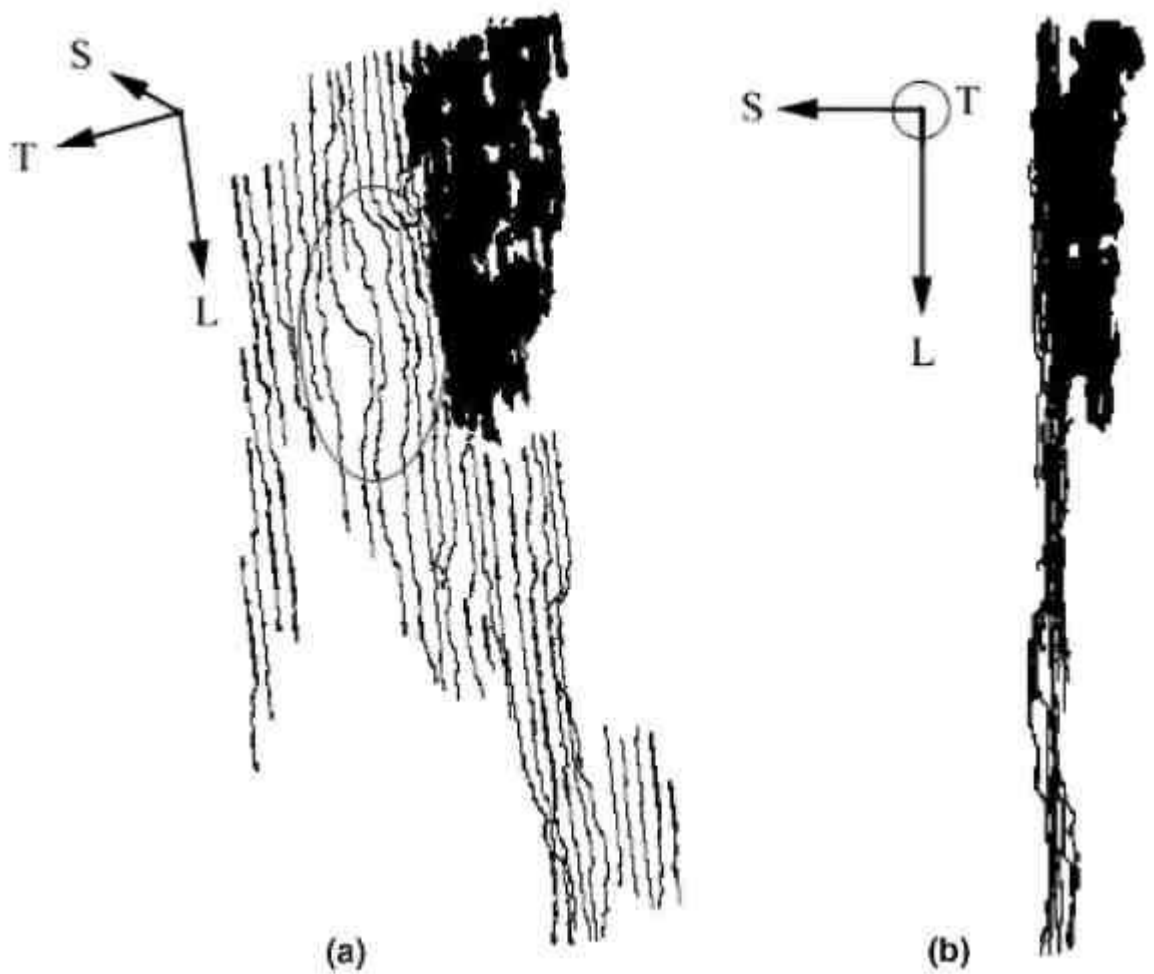

Fig. 7. 3-D reconstruction of a sharp IGC fissure from serial 2-D cross-sections, shown at different angles. (a) The selective grain attack site is indicated as a dark region in the top right. The sharp IGC fissure grew from the side and bottom. (b) From this angle it is clear that the sharp IGC fissure only grew along one side of the selective grain attack.

\subsection{Sharp IGC fissure kinetics}

Fig. 8 shows the sharp IGC fissure length as a function of fissure penetration time of the as-received AA7178 in high humidity $(96 \% \mathrm{RH})$. The data is scattered, especially for the time at around $500-600 \mathrm{~h}$, where the sharp IGC fissure lengths in the L direction were found to vary from 100 to $400 \mu \mathrm{m}$. Some of the samples had more than one penetration site when the humidity test was stopped. Serial sectioning was performed on as many of those sites as possible. On one $\mathrm{L}$ sample, a first penetration site was evident after $464 \mathrm{~h}$ and a second site after $512.5 \mathrm{~h}$. Examination by serial sectioning found that the sharp IGC fissure depths were 103.7 and 360.5 $\mu \mathrm{m}$ respectively. Apparently the first fissure that emerged from the sample grew slower than the 
second fissure that emerged. Therefore, this approach determines a range of sharp IGC fissure growth rates, not only the fastest sharp IGC fissure growth rates, and it provides the rates of long sharp IGC fissures, i.e. the ones that penetrated to the backside.

Anisotropic localized corrosion kinetics due to microstructural anisotropy of the materials have been reported for AA2024-T3 and AA7xxx alloys [2,3,7,8]. The grain dimensions of this material indicate that the IGC path in the T direction should be longer than in the L direction because of jogs at grain intersections. Therefore, the sharp IGC fissure rates should be slower in the $\mathrm{T}$ direction than in the $\mathrm{L}$ direction. However, no difference is seen in Fig. 8. It should be noted that only thin foil samples were used in this work. For thin foils, the sharp IGC fissure path could be only along one grain so that the rate in $\mathrm{T}$ direction should not be different than that in $\mathrm{L}$ direction. The results for different humidity and samples in different tempers presented below were all from L-oriented samples.

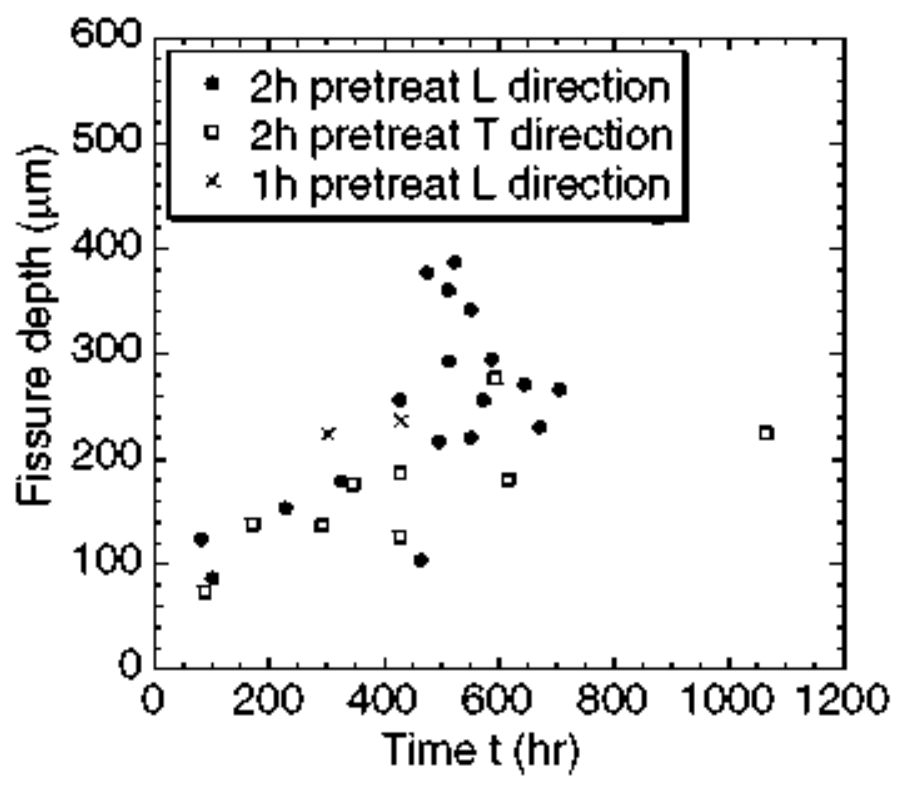

Fig. 8. Sharp IGC fissure rates of the as received wingskin AA7178 at high humidity (96\% RH) with different electrochemical pretreated time and sample orientations.

Most samples were electrochemically pretreated in $1 \mathrm{M} \mathrm{NaCl}$ at $-725 \mathrm{mV} \mathrm{SCE}$ for two hours. Fig. 8 includes two data points for samples pretreated for only one hour. The sharp IGC fissure kinetics were the same as for the samples pretreated for the longer time. From the kinetics of selective grain attack measured by the foil penetration technique, pretreatments of one and two hours were expected to produce selective grain attacks with longest depths of 240 and 300 $\mu \mathrm{m}$, respectively [4]. However, the foil penetration technique determines the fastest localized corrosion rates, and selective grain attack sites with a range of shorter depths could be generated by a given pretreatment time. Furthermore, as shown in Fig. 6, the sharp IGC fissures did not always initiate from the bottom of a selective grain attack. Pretreatment for either one or two hours generated selective grain attack of sufficient depth to trap an aggressive environment. As a result, the sharp IGC fissure growth rates were essentially independent of the size of the selective grain attack. 


\subsection{Humidity effects}

In this study the corrosion kinetics were measured during atmospheric exposure, not in aqueous environments. It is therefore of interest to know the effect of RH on the sharp IGC fissure growth kinetics.

Fig. 9 shows the sharp IGC fissure growth kinetics of the as-received AA7178 in atmospheres with different humidity from $58-96 \% \mathrm{RH}$. The electrochemical pretreatment on each sample was same: $2 \mathrm{~h}$ in $1 \mathrm{M} \mathrm{NaCl}$ at $-725 \mathrm{mV} \mathrm{SCE}$. The sharp IGC fissure kinetics are seen to be independent of the RH in the range studied. Fig. 10 shows an unetched cross section of a sample that was electrochemically pretreated and then stored in a dessicator for 5 months prior to sectioning. Sharp IGC fissures are seen in this figure (pointed out by arrows), indicating that they can grow even in extremely dry environments.

The lack of dependence of fissure growth rate on RH is interesting, especially in light of recent findings showing that the rate of exfoliation of the same material in humid environments depends strongly on RH, and that exfoliation ceases at an RH of 56\% [15]. In that work, slices of AA7178 plate were given similar electrochemical pretreatments prior to humidity exposure, so selective grain attack sites were created in both types of samples. The difference is that the whole slice was treated and exposed to humidity, allowing exfoliation attack from the edges. In this work, only a limited region of the sample surface was exposed and the surrounding unexposed region provided a constraint on the material in the exposed area so the corrosion took the form of sharp IGC fissures.

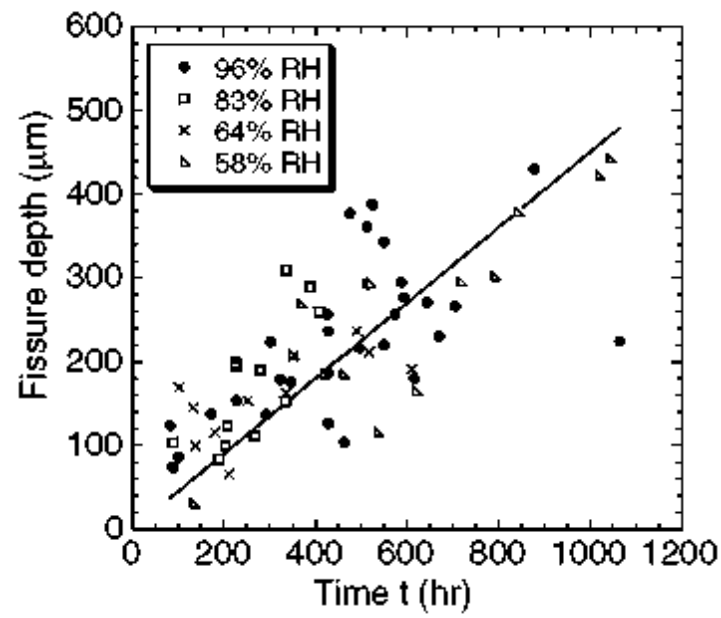

Fig. 9. Sharp IGC rates of the as received wingskin AA7178 in different humidity. The kinetics seem to be independent of humidity. A dash line is a Wt of all of the data to a straight line.

It is clear that the external environment has a very different influence on sharp IGC fissures and exfoliation corrosion. The pretreatment selective grain attack sites in both types of samples contained aggressive environment that resulted in further corrosion upon removal to a humid atmosphere. Drying of the environment in a selective grain attack pit would result in the precipitation of an aluminum hydroxychloride product. It has been reported that the critical humidity for a partially hydrolyzed aluminum chloride, $\mathrm{Al}(\mathrm{OH})_{3-x} \mathrm{Cl}_{x}$, is in the range of $40-95 \%$ depending on the degree of hydrolysis [16]. 


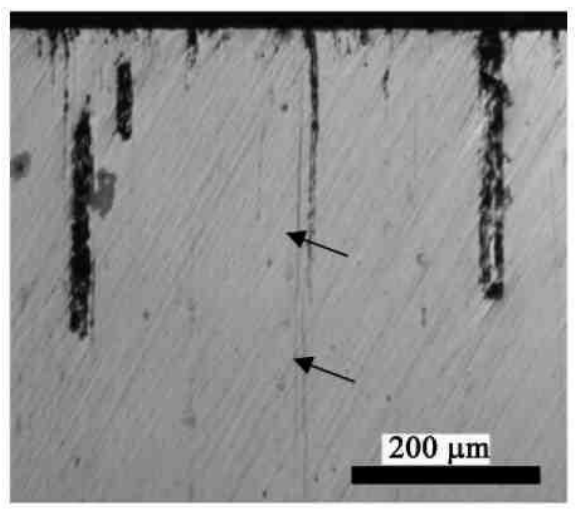

Fig. 10. Unetched cross section of AA7075-T6 sample following electrochemical treatment in $1 \mathrm{M} \mathrm{NaCl}$ at $-725 \mathrm{mV}$ for $5 \mathrm{~h}$ and storage in a dessicator for 5 months. Sharp IGC fissures were pointed out by arrows.

Therefore, it would be expected that RH should affect the state of the corrosion product and that at low enough RH the product would dry up and corrosion would cease. This is exactly what is observed for the case of exfoliation corrosion, where the exfoliation process opens up the corrosion site and provides access of the localized corrosion environment to the external atmospheric environment. However the samples used in this study of sharp intergranular fissures were constrained to prevent exfoliation and the external atmosphere apparently did not have ready access to the internal localized corrosion environment. Corrosion proceeded at the selective grain attack regions in the form of sharp intergranular Fissures and these Fissures were apparently rather isolated from the external environment. It is expected that in a very dry environment the water in the localized corrosion site eventually would be consumed by the creation of corrosion product and sharp IGC fissure growth would cease. However, this was not observed during the time periods used in this work.

The isolation of the local environment in a sharp IGC fissure from the external environment has implications for predictive models of aircraft corrosion. Because the land locations of aircraft are limited to air bases or airports, their exposure environments are relatively tractable. However, it cannot be assumed that the growth kinetics of these sharp IGC fissures will quickly change if the land base location changes, and a memory effect should be expected. Such is not the case for exfoliation corrosion [17].

\subsection{Temper effects}

It is well documented that AA7xxx in the over-aged temper exhibits better stress corrosion cracking (SCC) resistance than in the peak aged condition [18-24]. Most SCC testing is done in a solution environment, and it was just shown that humidity has little effect on the sharp IGC fissure kinetics. Therefore, it is also interesting to evaluate the temper effect on the sharp IGC fissure growth in humid environments. To determine the effects of temper on the sharp IGC fissure kinetics, samples of as-received AA7178 wingskin were reheat treated to T6 and $\mathrm{T} 7$ tempers.

Electrochemical pretreatment of the T6 and T7 samples was the same as for the asreceived wingskin samples: $2 \mathrm{~h}$ in $1 \mathrm{M} \mathrm{NaCl}$ at $-725 \mathrm{mV}$ SCE. The current density during electrochemical pretreatment for T6 and T7 samples was similar, about $1.4 \mathrm{~mA} / \mathrm{cm}^{2}$, but it was only $0.73 \mathrm{~mA} / \mathrm{cm}^{2}$ for as-received samples. Vickers hardness testing was performed to verify the 
temper. The hardness values were HV 198, 199, and 184 for as-received, T6, and T7, respectively, suggesting that the re-heat-treated T6 and T7 samples were in the desired tempers and that the as-received plate was in the T6 temper. However, handbook hardness values for 7178-T6 and -T7 are only HV 189 and 177, respectively [25]. It is interesting that the hardness of the as-received AA-7178 was similar to the T6 sample, but the current density during pretreatment was lower than that measured on both the T6 and T7 samples. It has been reported that corrosion resistance is improved in the over-aged condition [18-24]. Given these conflicting data, the exact temper of the as-received samples is still in question.

Only one RH, 96\%, was chosen to test the T6 and T7 samples, since the sharp IGC fissure rate was found to be independent of humidity. The results are shown in Fig. 11 along with previous results on the as-received AA7178 wingskin in the same RH. Despite the scatter, it is clear that the sharp IGC fissure growth rate for T6 temper was higher than for T7, which is consistent with reports in the literature that the over-aged condition (T7) is more resistant to corrosion than peak-aged condition (T6). Furthermore, the sharp IGC fissure growth rate for the as-received samples was slower than for both re-heat-treated samples, which again calls into question the exact temper of this material.

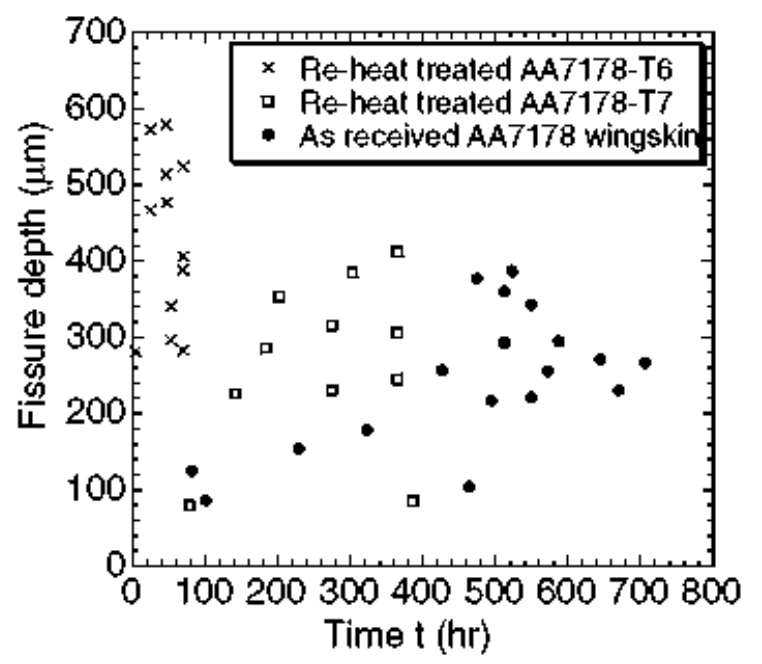

Fig. 11. Samples in different tempers were tested in $96 \%$ RH. The re-heat treated AA7178 shows higher corrosion rates and $\mathrm{T} 7$ is more resistant to sharp IGC fissures than T6.

To understand the effect of temper on sharp IGC fissure growth rate, the microstructures were examined by transmission electron microscopy (TEM). Several TEM samples were prepared from different locations of the as-received AA7178 plate. A variation of the microstructure was observed. It has also been found that localized corrosion varies across the plate as some locations are more susceptible than others [26]. As a result, it is difficult to analyze the microstructure of a whole plate and compare it to the other tempers. Therefore, in this work only the microstructure near sharp IGC fissures was examined and compared to understand the effect of temper on sharp IGC fissure growth rate.

The TEM samples were prepared using focused ion beam (FIB) sectioning to examine a location close to the sharp IGC fissures in each material. Fig. 12 shows TEM images of the asreceived, T6 and T7 samples near the locations of the sharp IGC fissures in each sample. The T7 matrix contains larger particles than the matrix of T6 and the as-received samples. 


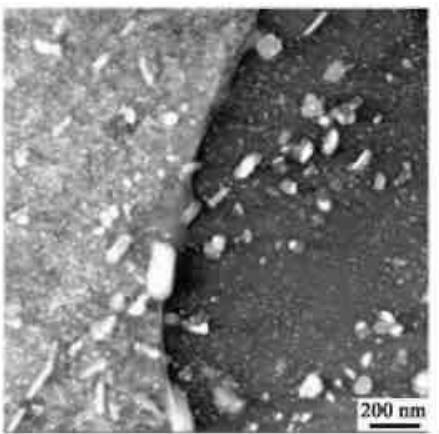

As-received

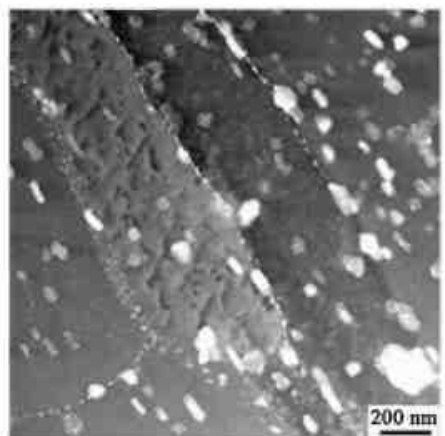

T6

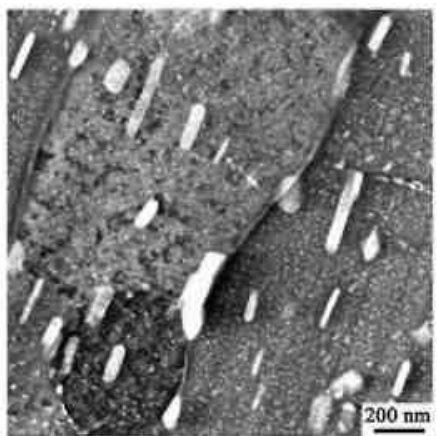

T7

Fig. 12. TEM images of the as-received, T6 and T7 samples showing the grain boundary microstructure. T6 has fine and continuous $\eta$ phase particles along the grain boundary while the $\eta$ phase particles are large and spaced at grain boundary in the as-received and $\mathrm{T} 7$ conditions.

At the grain boundary, the as-received and T7 have large and spaced particles while T6 shows a high density of fine particles. Quantitative TEM analysis using electron dispersive spectroscopy (EDS) showed that these particles have high contents of $\mathrm{Zn}$ and $\mathrm{Mg}$, suggesting that they are $\eta$ or $\eta$. It was reported that $\eta$ or $\dot{\eta}$ is more active than the matrix in AA7xxx [27,28]. It is possible that the fine particles in T6 grain boundaries resulted in a faster sharp IGC fissure growth rate and the absence of the small grain boundary particles in the as-received and $\mathrm{T} 7$ resulted in a slower sharp IGC fissure growth rate. The micro-structure of the as-received material is similar to that of T7, consistent with the rate of sharp IGC fissure growth.

\subsection{Sharp IGC fissure examination}

Fig. 13 is a secondary electron image of a sectioned IGC fissure prepared by FIB sectioning. The width of the sharp IGC fissure is about $200 \mathrm{~nm}$. A thin TEM sample containing a sharp IGC fissure was prepared by FIB. Analysis of the fissure by Electron Dispersive Spectroscopy detected $\mathrm{O}$ and $\mathrm{Cl}$, indicating that corrosion product filled the fissure crack.

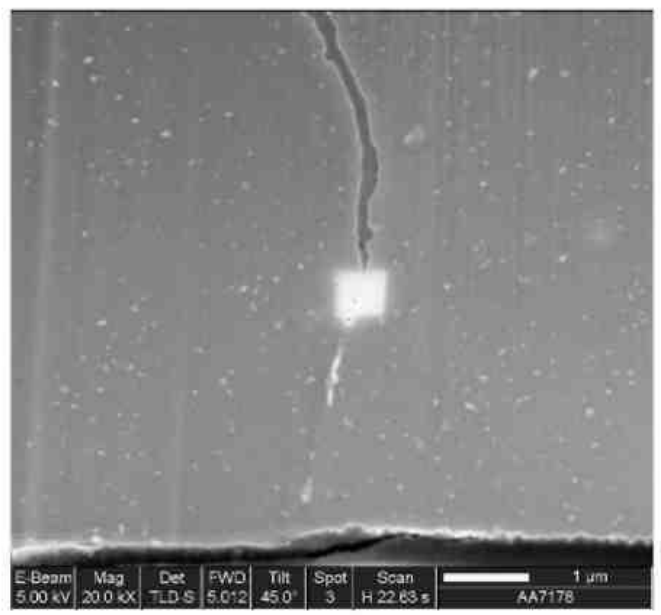

Fig. 13. A secondary electron image of a sectioned sharp IGC fissure prepared by FIB sectioning. The width of the sharp IGC fissure is around $200 \mathrm{~nm}$. 
The surface of a sharp IGC fissure was revealed by pulling apart a penetrated sample under tension and examining it by Scanning Electron Microscopy (SEM). Fig. 14 shows the surface of a fractured sample. The morphology of the fracture surface has three distinct regions. At low magnification it is easy to discern a dimple fracture area associated with the tensile overload (area C). The non-dimpled area is relatively planar, and at higher magnification it is possible to distinguish the selective grain attack region associated with the pre-treatment (area A) and the sharp IGC fissure area (area B). The selective grain attack region contains rough shallow pits on the fracture surface, whereas the sharp IGC fissure area is much flatter.

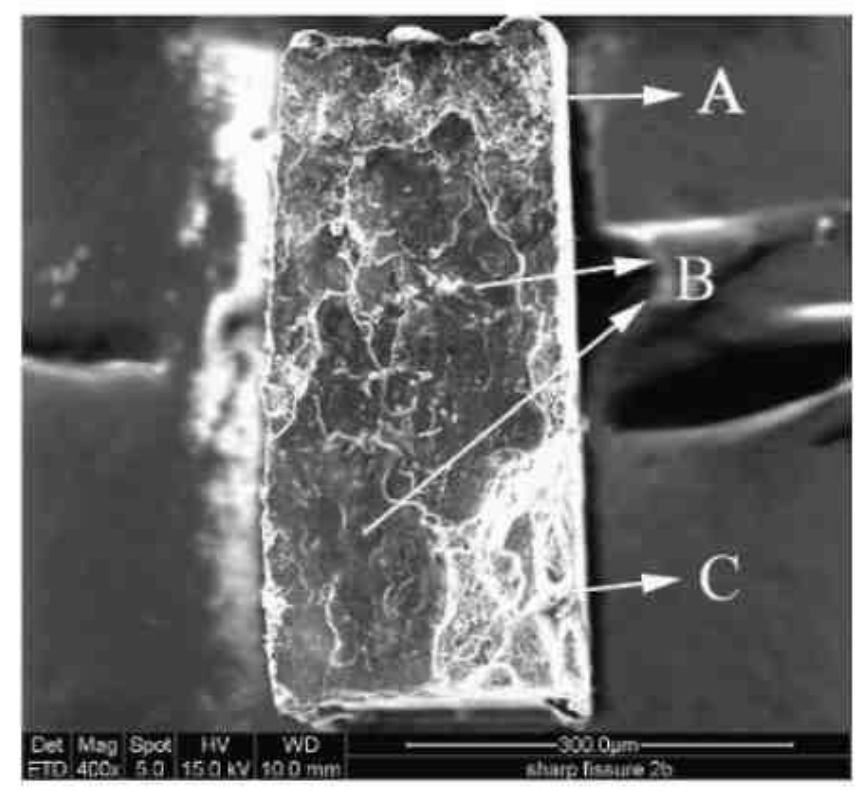

Fig. 14. Matching surfaces of a fractured sample indicate three distinct regions. A: selective grain attack from electrochemical pretreatment. B: sharp IGC fissures from humidity exposure. C: uncorroded ductile fracture region.

Sharp IGC fissure surfaces were analyzed by x-ray photoelectron spectroscopy (XPS). A dual Mg X-ray source was used and an area of $100 \mu \mathrm{m}$ diameter on matching sides of the sharp IGC fissure region of a fracture sample was analyzed. The spectra of $\mathrm{O}, \mathrm{C}, \mathrm{Cl}$ and $\mathrm{Al}$ lines were recorded as well as $\mathrm{C}$ for calibration. Fig. 15 shows the spectra of $\mathrm{Al}, \mathrm{O}$ and $\mathrm{Cl}$. The $\mathrm{Al} 2 \mathrm{p}$ line can be fitted with two peaks at binding energies of 74.2 and $75.5 \mathrm{eV}$, which can be identified as aluminum oxide and aluminum hydroxychloride, respectively $[29,30]$. The $\mathrm{O} 1 \mathrm{~s}$ peak is primarily oxide, and a $\mathrm{Cl} 2 \mathrm{p}$ peak was also detected, which supports the designation of the $\mathrm{Al} 2 \mathrm{p}$ hydroxychloride peak. These observations support the notion that the sharp IGC fissures were filled with aluminum oxide and hydroxychloride corrosion products that cracked upon drying.

\subsection{Sharp IGC fissure mechanism}

AA7xxx alloys are known to be susceptible to intergranular stress corrosion cracking (IGSCC) when subjected to a tensile stress in an aggressive environment [20,21,31-35]. However, in this study the sharp IGC fissures grew in samples that were unstressed. Furthermore, the pretreated area from where the sharp IGC fissures grew was surrounded by material that was not exposed during pretreatment, and this region acted to constrain the material 
from opening up as in the case of exfoliation corrosion. Nonetheless, it is likely that the sharp IGC fissure phenomenon is very similar to SCC. Like exfoliation corrosion, the fissures could grow as a result of self-stressing by voluminous corrosion product formed at the grain boundary region. It has recently been shown that very low stresses (as low as 10\% of the yield stress) normal to the elongated microstructure in wrought aluminum alloys can increase localized corrosion penetration rates significantly [36]. For the sharp fissures in this study, the wedging stress from the corrosion product is apparently sufficient to drive cracking despite the constraining effect of the unexposed surrounding material. There is considerable evidence for the creation of corrosion product in the sharp IGC fissures. As mentioned, corrosion product was observed to creep out of the sharp IGC fissure onto the backside of the sample upon penetration, and the sharp IGC fissure surfaces were found to be covered with aluminum hydroxychloride.
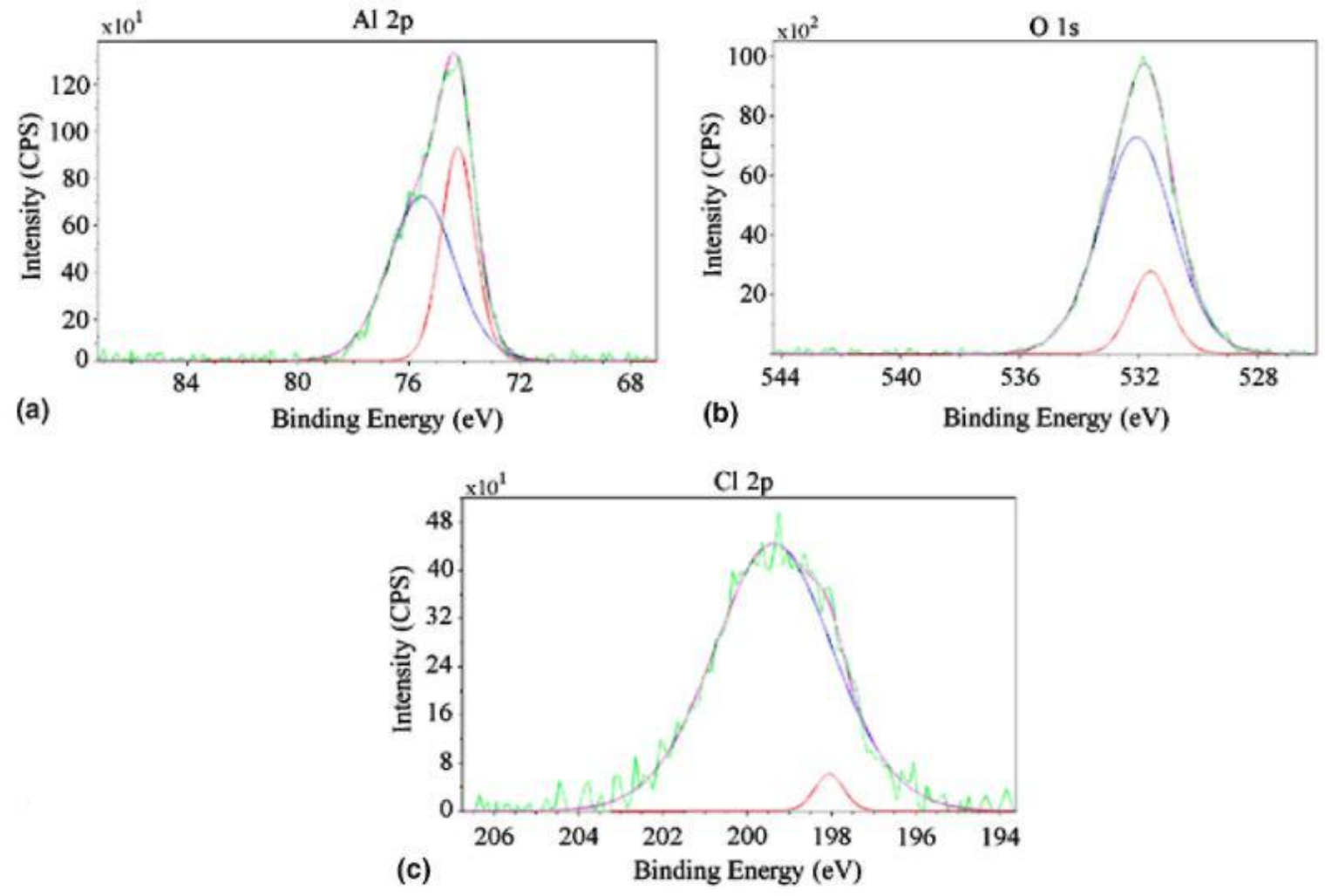

Fig. 15. XPS spectra of $\mathrm{Al}, \mathrm{O}$ and $\mathrm{Cl}$ on the layer of mud-cracking in the sharp IGC fissure area.

Fig. 9 shows that the rate of the sharp IGC fissure growth in the as-received AA7178 is approximately linear. A constant rate of crack growth is observed over a broad range of $\mathrm{K}_{\mathrm{I}}$ level in the stage II region of SCC. [19,20,31,33,35,37] It was mentioned earlier that the temper condition of the as-received AA7178 is unknown, although it seems to close to the T7 temper (Fig. 11). The sharp IGC fissure growth rate is around $4.5 \times 10^{-4} \mathrm{~mm} / \mathrm{h}$ for the as-received AA7178 in Fig. 9 and it is about $7.3 \times 10^{-3} \mathrm{~mm} / \mathrm{h}$ for T6 in Fig. 11 . The reported crack growth rates of AA7075-T6 and -T7 in $0.6 \mathrm{M} \mathrm{NaCl}$ are around $2 \times 10^{-2}$ and $4 \times 10^{-4} \mathrm{~mm} / \mathrm{h}$, respectively [19]. So the sharp fissure growth rates in AA7178 are similar in magnitude to the stage II SCC growth rates for AA7075 in seawater. This supports the notion that the fissure growth mechanism is related to SCC. 


\section{Conclusions}

Corrosion morphology in AA7xxx is different in different environments. Selective grain attack is observed during exposure in a $\mathrm{NaCl}$ solution and sharp IGC fissures form in a humid environment. A new approach was developed to quantify the sharp IGC fissure kinetics in AA7178 wingskins in different humid environments. Samples were also heat treated to examine the temper effect. The following observations were made:

1. This new approach determines a range of sharp IGC fissure rates in high humidity, not only the fastest rates, and it provides the rates of long sharp IGC fissures.

2. Each sharp IGC fissure is associated with a selective grain attack site, which provides an aggressive environment for sharp IGC fissures to grow in humid environments.

3. The sharp IGC fissure rates in T direction are similar as in L direction for thin foils; the sharp IGC path is very straight in both the $\mathrm{T}$ and $\mathrm{L}$ directions.

4. There seems to be no effect of varying electrochemical pretreatment time, but the pretreatment attacks are required for sharp IGC fissures to grow.

5. The sharp IGC fissure growth rates were independent of humidity in the range of $96 \%$ to $58 \%$ RH due to lack of connection of the local sites to the external environment. Sharp IGC fissures were even observed to grow in a dessicator.

6. The re-heat-treated AA7178 had higher corrosion rates than the as received material, and the T7 temper was more resistant to sharp IGC fissure than T6. The faster sharp IGC fissure rate in T6 could be due to fine and continuous $\eta$ phase particles at the grain boundary.

7. The sharp IGC fissure growth is caused by stress corrosion cracking associated with stresses generated by the intergranular corrosion product.

\section{Acknowledgements}

The authors acknowledge funding from the Aging Aircraft Division of ASC in support of the Aeronautical Enterprise Structures Strategy with a contract through S \& K Technologies.

\section{References}

[1] R. Kinzie, Corrosion suppression: managing internal and external aging aircraft exposures, in: Proceedings of 6th FAA/DoD/NASA Aging Aircraft Conference, San Francisco, CA, 2002.

[2] T.S. Huang, G.S. Frankel, B. Farahbakhsh, D. Peeler, Localized corrosion growth kinetics in Al alloys, in: Proceedings of 6th FAA/DoD/NASA Aging Aircraft Conference, San Francisco, CA, 2002.

[3] T. Huang, X. Zhao, G.S. Frankel, B. Zoofan, S. Rokhlin, Growth kinetics of intergranular and exfoliation corrosion in AA7178, in: Proceedings of Tri-Service Corrosion Conference, Las Vegas, 2003.

[4] T.-S. Huang, G.S. Frankel, Intergranular corrosion morphology and growth kinetics in AA7075 and AA7178, in: P. Schmuki, D.J. Lockwood, Y.H. Ogata, M. Seo, H. Issacs (Eds.), Third International Symposium on Pits and Pores: Formation, Properties and Significance for Advance Materials, The Electrochemical Society, Honolulu, HI, 2004.

[5] F. Hunkeler, H. Böhni, Corrosion 37 (1981) 645-650.

[6] A. Sehgal, G.S. Frankel, B. Zoofan, S.I. Rokhin, J. Electrochem. Soc. 47 (1) (2000) 140-148. [7] W. Zhang, G.S. Frankel, Electrochem. Solid-State Lett. 3 (2000) 268-270.

[8] W. Zhang, G.S. Frankel, J. Electrochem. Soc. 149 (11) (2002) B510-B519.

[9] X. Liu, W. Zhang, G.S. Frankel, in: R.H. Jones (Ed.), Chemistry and Electrochemistry of Corrosion and Stress Corrosion Cracking, TMS, 2001, p. 543.

[10] M.O. Speidel, M.V. Hyatt, in: M.G. Fontana, R.W. Steahle (Eds.), Advances in Corrosion Science and Technology, vol. 2, Plenum Press, New York, 1972.

[11] R.C. Weast (Ed.), Handbook of Chemistry and Physics, 61th ed., CRC Press, 1980.

[12] W. Zhang, G.S. Frankel, Electrochem. Acta 48 (2003) 1193-1210.

[13] J.R. Kremer, D.N. Mastronarde, J.R. McIntosh, J. Struct. Biol. 116 (1996) 71-76. 
[14] D.N. Mastronarde, J. Struct. Biol. 120 (1997) 343-352.

[15] X. Zhao, Ph.D. Thesis, The Ohio State University, 2005.

[16] N. Le Bozec, D. Persson, A. Nazarov, D. Thierry, J. Electrochem. Soc. 149 (9) (2002) B403-B408.

[17] G.S. Frankel, T.-S. Huang, X. Zhang, in: P. Marcus (Ed.), Localized Corrosion Growth Kinetics in AA7xxx Alloys, Passivity, vol. 9, Elsevier, 2005.

[18] T.D. Burleigh, Corrosion 47 (2) (1991) 89-98.

[19] J.K. Park, Mater. Sci. Eng. A 103 (1988) 223-231.

[20] J.R. Pickens, T.J. Langan, Metall. Trans. A 18A (10) (1987) 1735-1744.

[21] M. Puiggali, A. Zielinski, J.M. Olive, E. Renauld, D. Desjardins, M. Cid, Corros. Sci. 40 (4-5) (1998) 805-819.

[22] T.C. Tsai, J.C. Chang, T.H. Chuang, Metall. Mater. Trans. A 28A (10) (1997) 2113-2121. [23] M.P. Mueller, A.W. Thompson, I.M. Bernstein, Corrosion 41 (3) (1985) 127-136.

[24] J. Onoro, C. Ranninger, Mater. Sci. 35 (4) (1999) 509-514.

[25] Metal Handbook. ASM International, 10th ed., vol. 2 - Properties and Selection: Nonferrous Alloys and Special-Purpose Materials, 1990.

[26] T.-S. Huang, Ph.D. Thesis, The Ohio State University, 2005.

[27] E. Mattson, L.O. Gullman, L. Knotsson, R. Sundberg, B. Thundal, Br. Corros. J. 6 (2) (1971) 73-83.

[28] A.J. Sedriks, A.S. Green, D.L. Novak, in: R.W. Staehle, B.F. Brown, J. Kruger, A. Agarwal (Eds.), Localized Corrosion, NACE, Houston, TX, 1971.

[29] J.F. Moulder, W.F. Stickle, P.E. Sobol, K.D. Bomben, Handbook of X-Ray Photoelectron Spectroscopy: A Reference Book of Standard Spectra for Identification and Interpretation of XPS Data. Reissue ed: Physical Electronics, 1995.

[30] G.E. McGuire, G.K. Schweitzer, T.A. Carlson, Inorg. Chem. 12 (10) (1973) 2450-2453. [31] P.K. Poulose, J.E. Morral, A.J. McEvily, Metall. Trans. 5 (June) (1974) 1393-1400.

[32] G. Geschwind, G.C. Soltz, P.N. Adler, Corrosion 26 (7) (1970) 165-168.

[33] K. Rajan, W. Wallace, J.C. Beddoes, J. Mater. Sci. 17 (10) (1982) 2817-2824.

[34] D. Najjar, T. Magnin, T.J. Warner, Mater. Sci. Eng. A238 (2) (1997) 293-302.

[35] R.J. Gest, A.R. Troiano, Corrosion 30 (8) (1974) 274-279.

[36] X. Liu, G.S. Frankel, B. Zoofan, S.I. Rokhin, Corros. Sci. 46 (2004) 405-425.

[37] R. Hermann, Corrosion 44 (10) (1988) 685-690. 